\title{
APROXIMACION A UN HOMBRE \\ DEL BARROCO: NOTAS EN TORNO A FRANCISCO CASCALES
}

\author{
Cayetano MAS GALVAÑ \\ Universidad de Alicante
}

Lo que en principio nos propusimos realizar, al abordar el presente trabajo, se reducía a un simple análisis de la influencia que los falsos cronicones ejercieron en las obras de carácter histórico escritas por el licenciado Francisco Cascales (1567-1642). Despertó nuestro interés sobre este particular la inédita Historia del Colegio de San Fulgencio con algunas antigüedades de Cartagena y memoria de sus obispos y mártires (1), último de los trabajos historiográficos de Cascales y fruto de su senectud (datable en torno a 1635-1639). Al pronunciarse sobre ella, el biógrafo de Cascales, Justo García Soriano, lo hacía de modo peyorativo, por considerarla producto de una "lamentable equivocación»(2) cometida por el, en su juicio, eximio humanista y crítico. Aun sin negar la certeza que en el fondo contiene esta apreciación, el prisma desde el que nosotros contemplamos la obra de Cascales difiere radicalmente del adoptado por don Justo. Lejos de pretender cantar las excelencias del licenciado o de dirigirle una "anacrónica" reprimenda sobre sus errores, tratamos de explicar las razones de aquella "equivocación". Por lo tanto, no efectuamos un análisis pormenorizado de la obra, sino que hemos intentado descubir en el conjunto de la producción cascaliana las claves que llevaron al preceptor murciano a basar casi enteramente en los falsos cronicones la Historia... en cuestión. De ahi que nos remontemos hasta realizar, sobre el conjunto de las obras de Cascales, una reconsideración global de su figura. El resultado ha sido la comprobación de un hecho determinante, firmemente enraizado en la base de su mentalidad y de sus actitudes, que práctica- 
mente puede ser elevado a denominador común tanto de su obra como de su ideología. Como tantos otros escritores que tomaron parte activa en el montaje que supuso la cultura del Barroco(3), Cascales, a través de una clara toma de posición en favor de los valores de la sociedad estamental, responde ante la misma con su compromiso beligerante en favor del modo de vida que determinan y del tipo de sociedad que ordenan y jerarquizan. Los temas básicos que caracterizan su producción escrita (el clasicismo literario, la apología, la intención moralizadora, el nacionalismo, e incluso su propio humanismo) vienen, en efecto, a articularse en gran medida sobre tal punto de partida. Sin embargo, un trabajo pormenorizado que desarrolle plenamente la cuestión - que estamos convencidos resulta detectable hasta en las más intimas fibras del tejido intelectual de nuestro humanista - no tiene cabida dentro de los estrechos márgenes que marca un artículo. Sin embargo, resulta necesaria la reconsideración de algunos puntos tocantes a la biografía y a la bibliografía sobre Cascales.

\section{Bibliografía: estado de la cuestión}

Como acabamos de dejar apuntado, la simple consulta de la bibliografía existente en torno al licenciado revela la carencia absoluta de una obra de conjunto que efectúe una reconsideración global de su figura, apoyada en una investigación profunda y pormenorizada bajo la luz de las últimas aportaciones aparecidas sobre la cultura del Barroco español. Obra que, al tiempo de ubicar correctamente dentro de ésta un personaje poco recordado y aún menos estudiado en las obras de carácter general, supondría posiblemente una aportación no despreciable sobre algunos de los aspectos en la trayectoria seguida por nuestro humanismo durante aquel periodo.

Dos líneas podemos diferenciar en la bibliografia cascaliana. De un lado, encontramos la fecunda tradición local murciana, fundamentalmente erudita, en la que el licenciado nunca ha dejado de ser centro de interés. El hito más importante quedó establecido con los trabajos constantes e infatigables que le dedicó don Justo García Soriano. En su virtud, conocemos los detalles bio-bibliográficos más importantes sobre Cascales. Sin embargo, están sometidos a un cierto desenfoque, proporcionado por una intención reivindicativa - muy meritoria, cuando Cascales era una figura prácticamente desconocida-, de prisma demasiado localista. Por otra parte, concebido su libro El humanista Cascales... (4), en una línea polémica muy a lo Menéndez Pelayo, ha quedado desfasado en muchos de sus juicios. Sin embargo, recordémoslo, es realmente la única obra de conjunto con que contamos. Esta veta erudita murciana, que ha ido arrojando intermitentemente datos de indudable interés sobre puntos oscuros en la biografía de Cascales, y que ha acometido la reedición de alguna de sus obras(5), culmina recientemente con el libro de Jerónimo García Servet, 
El humanista Cascales y la Inquisición murciana(6). En él se nos confirma un hecho de excepcional trascendencia en Cascales, ya barruntado por Garcia Soriano: su ascendencia conversa.

La segunda línea bibliográfica a la que aludimos es la contenida en las obras de carácter general. Dentro de éstas, contamos con toda una pléyade de citas que hacen referencia a nuestro autor. En su mayoria son historias de la literatura y obras que tratan sobre teoría literaria y, por tanto, se ocupan casi exclusivamente de las ideas estéticas del licenciado(7), 10 que de alguna manera nos hace de nuevo perder la deseable visión de conjunto sobre su pensamiento. El punto de arranque de esta línea se sitúa en el "redescubrimiento" cascaliano que tuvo lugar en el transcurso de las polémicas dieciochescas acerca del neoclasicismo y del teatro; recogida por Menéndez Pelayo(8), ha pervivido hasta fructificar, hace pocos años, en el mejor trabajo crítico de que hoy disponemos sobre el licenciado en general y en el terreno de sus ideas estéticas en particular. Nos referimos a la obra de Antonio García Berrio, Introducción a la poética c/asicista: Cascales( ${ }^{(9)}$. Pero, sin embargo, este desplazamiento hacia el campo literario, generalmente observable en ambas líneas bibliográficas, ha causado que conozcamos tan bien las ideas estéticas del preceptor, como que ignoremos todo lo demás que pudiera atañer a su pensamiento. De modo especial, y por lo referente al otro gran terreno en la actividad de Cascales (el historiográfico), vemos reducido nuestro horizonte crítico al juicio - reflejado por Garcia Soriano- que ya formulase el impresor Francisco Benedito en el prólogo a su edición de los Discursos históricos..., efectuada en 1775(10). Alli, se señalaba la influencia recibida de los falsos cronicones. Con alguna adición sobre la concepción historiográfica del licenciado, el juicio se ha venido repitiendo posteriormente.

En efecto, una característica apreciable en toda la bibliografia que estamos tratando - salvo alguna excepción- es la del recurso a citar algunos párrafos cascalianos, machaconamente. Citas que en su mayoría han sido extraidas de sus Cartas filológicas, y que, a fuerza de ser repetidas hasta la saciedad, han pasado a convertirse en tópicos desnaturalizados, poco gratos, y en muchas ocasiones tratados con poca fortuna. A alguno de ellos (como el de la referencia a los "cándidos humanistas" o el de su queja sobre el nulo provecho de las letras) haremos alusión más adelante.

\section{Datos biográficos: los condicionantes sociológicos}

Muy sucintamente, los hitos básicos de obligada referencia que marcan la biografía de Cascales, son los siguientes. Nacido en Murcia en 1567 , muy pronto fue destinado al estudio de la gramática, para (en fecha aún no determinada) obtener el grado de licenciado en Humanidades (igualmente, desconocemos en qué Universidad). Alrededor de 1585 se alista en el ejército y marcha a Flandes. Su experiencia militar le permitió 
adquirir ese "saber de vida" al que después tanto recurriría, al tiempo que le proporcionó el conocimiento directo del humanismo a la sazón practicado en Francia y Bélgica. Más tarde, antes de 1594, regresa a su región de origen, de donde ya no habria de salir jamás (salvo algún corto viaje). En la búsqueda de una profesión que le proporcione la necesaria seguridad económica, en 1597 es admitido como preceptor de gramática por el Ayuntamiento de Cartagena, percibiendo un sueldo de treinta mil maravedises anuales. Vacante en 1600 la cátedra de gramática de la Maestrescolía de la catedral murciana, recientemente incorporada al Seminario de San Fulgencio, se presenta a la oposición y la aprueba. El 13 de octubre de 1601 resulta elegido catedrático, con un sueldo asignado de ciento treinta ducados en moneda, más alguna percepción en frutos (trigo, cebada, vino, aceite y otros)(11). En Murcia pasó el resto de su vida, expirando el 30 de noviembre de 1642, cinco meses después de jubilarse. Es precisamente en este periodo de su vida, una vez abandonada la milicia, en el que escribirá todas sus obras (12).

En relación con esta estructura vital, se encuentra una serie de cuestiones de primordial importancia para la comprensión de sus actividades. Obviamente, las condiciones de todo tipo presentes en cualquier sociedad histórica están incidiendo, en un proceso dialéctico, sobre las notas biográficas propias de cada personaje. De la modulación particular que, en cada caso, adopte ese ajuste entre unas y otras dependerá la orientación general de la respuesta que el hombre en cuestión dé a la sociedad en que vive. Así pues, resulta necesario referir los determinantes sotiológicos y económicos que vivió el lincenciado al marco de su sociedad y más concretamente a su (en términos sociológicos) grupo de referencia. En este caso, a la sociedad estamental y la nobleza (particularizando, si se quiere, al grupo privilegiado de la Murcia de la época).

El primer dato a tomar en consideración es el del origen converso de Cascales, que, como hemos indicado, ha sido confirmado por Garcia Servet ${ }^{(13)}$. Desde su nacimiento, el futuro licenciado se vio colocado en una situación muy peculiar y sin duda dolorosa, que L. Gil califica de «legítima bastardían (14). Su padre, el mercader Luis de Ayllón, pertenecía a una familia conversa procedente de Mondéjar. Afincado en Murcia, alcanzó el cargo de jurado en el concejo municipal. Su madre, Leonor de Cascales, descendia de una de las familias integrantes de la hidalguia murciana. Relajado y quemado en efigie Luis de Ayllón, bajo la acusación de herejía (1564), doña Leonor pasó a convertirse en la viuda legal de una persona viva. Nacido tres años más tarde, Francisco Cascales (nótese la omisión del de y la utilización del sólo apellido materno) quedaba condenado de por vida a no poder obtener el reconocimiento legal de su linaje - no por ser bastardo, sino por la tacha de herejía-, sabiéndose y sintiéndose noble. No dudamos de que esta traba de origen está provocando el estado de tensión 
tan bien caracteriza al licenciado. Estado que se descargaba esporádicamente, teñido de ironia y amargo sarcasmo (cuando no de claro resentimiento) al hablar de su vida y de sus iguales, los nobles. Tensión que es a la vez centripeta y centrífuga: huyendo constantemente de su origen (que nunca refiere), la huida la orienta precisamente hacia su mismo grupo. Ninguna prueba mejor de tal esfuerzo aproximativo que el conjunto de su obra. Y a juzgar por sus relaciones y por el prestigio obtenido en su madurez, local e incluso nacional, sus esfuerzos, en principio vanos(15) terminaron fructificando.

Que Cascales consiguió hacer efectiva su integración - de un modo u otro- en el seno del grupo al que se sentía pertenecer, resulta evidente cuando se analizan las relaciones que sostuvo(16). En primer lugar, sus matrimonios. Dos de sus tres mujeres (precisamente las últimas, Luisa de Contreras y Juana Ferrer) llevan apellidos de la hidaiguía murciana. En cuanto al resto de las relaciones, literarias y personales, predominantemente se trata de nobles - algunos de la alta nobleza foránea, y la mayoria restante, hidalgos de su ciudad y región-. En cuanto a las específicamente literarias, manifiestan el conocimiento que trabó de los círculos intelectuales de su época, de donde invariablemente recoge elogios (son constatables muy escasas críticas abiertas). Tampoco podemos olvidar, en este terreno, la cordial relación con un personaje tan significativo en nuestro Barroco como Lope de Vega, y mucho menos aún con Saavedra Fajardo.

Luis Gil, en su Panorama social del humanismo español (1500-1800) ha captado la importancia tipificadora que revisten algunos textos de Cascales, alusivos sobre todo a la condición social del humanista, colocándolos en relación con el contexto general del humanismo español durante la época. Hallamos en estas citas (todas de las Cartas filológicas) al Cascales que da por perdida la batalla sostenida por los humanistas durante el siglo XVI frente a la élite cultural (en un puro sentido sociológico) que entonces constituían los teólogos y los juristas, pero que no renuncia a recordar a estos últimos el poder que otorgaba el conocimiento profundo de la gramática, de las fuentes del saber en su lengua original; al Cascales que, en definitiva, se repliega en una actitud defensiva, como el resto de sus colegas, ante el clima de hostilidad generalizada creado por aquéllos y vertido contra los, despectivamente calificados, "gramáticos»:

"Cosa ridícula parecerá a los ojos y juicio de los doctos el atrevimiento mío de predicar, ya en voz alta, ya con animada pluma, gloriosas alabanzas de la gramática; que sólo el nombre de ella, según su baja opinión, abate la mayor soberbia, si alguna pueda tener un gramático (...) Humilde confieso el bajo principio de que nacimos, pero conozcan todos los hombres doctos que somos sus progenitores, y que nos deben 
el ser que tienen: que sin nosotros, ni el teólogo pisara los pavimentos del cielo; ni el físico anduviera por los soterráneos y secretos poros de la Tierra (...); ni el astrólogo (...) ni el médico (...); ni el jurisconsulto (...) ¿De qué os reis? Oíd al gran Augustino (...) Grammatica est janua omnium scientiarum».(17)

Sin perjuicio de que volvamos sobre estos textos, no infrecuentes en Cascales, dejemos anotado por ahora que ésta es fundamentalmente una reivindicación del prestigio que piensa debe corresponder a su profesión. Una profesión que, estamos seguros, Cascales ha tenido que escoger por las circunstancias que su origen le impuso.

Las reivindicaciones de un status mejor no cesan en este punto. Son igualmente detectables en el terreno, más prosaico, de sus ingresos y gastos económicos. Otro de los textos que ha sido convertido en tópico clarifica cuanto decimos. Decía Cascales, entre bromas y veras:

"¡Oh letras! ¡Oh infierno! ¡Oh carniceria! ¡Oh muerte de los sentidos humanos! O seáis rojas, o seáis negras; que de esta manera sois todas. Por lo rojo sois sangrientas, sois homicidas; por lo negro sois simbolo de la tristeza, del luto, del trabajo, de la desdicha. ¿Quién me metió a mi con vosotras? Cincuenta años ha que os sigo, que os sirvo como esclavo: ¿qué provecho tengo?, ¿qué bien espero? En la tahona de la gramática estoy dando vueltas peor que rocín cansado (...) ¿qué premio me aguarda?»(18)

Efectivamente, no cabe la menor duda de que Cascales pasó muy reales y persistentes necesidades económicas (19), sólo soslayadas, de modo esporádico, por algún que otro ingreso siempre de carácter extraordinario(20). Los salarios percibidos por la docencia, que distan de ser pingües, se ajustan a la media nacional, bastante baja, que venian cobrando los preceptores, a la sazón ocupantes de la posición más baja en la sociología del saber. En consecuencia, Cascales - como otros muchos gramáticos-, no podía sentir excesivo interés por sus clases, manifiesto en las acusaciones de abstinencia que le dirigió reiteradamente el cabildo catedralicio. Reciprocamente, también conocemos los apremios que el licenciado dirigió a aquél, causados por la irregularidad en el cobro del salario. Pero la alusión al escaso "premio" de su oficio evidencia el descontento por el desempeño de un oficio que, sobre todo, no es el propio de su condición. En abono de esta interpretación, cuando registra una pequeña mejoría económica, documentada por Torres Fontes para el periodo 1631$1633^{(21)}$, le encontramos vendiendo la hoja de morera de una tierra propiedad del cabildo, haciendo un préstamo de cien ducados, recibiendo una herencia, subarrendando una casa, comprando una viña y proyectando crear una bodega. A su muerte, nada de todo esto quedaba. ¿Se trata de esfuerzos tendentes a equiparar su posición, por lo menos en lo económi- 
co, a la que correspondería a un hidalgo, al fin y al cabo, a lo que Cascales era y se sentía? Sin la menor duda, la respuesta a esta cuestión debe ser afirmativa.

Un último punto clarifica cuanto venimos exponiendo sobre el ideal de vida nobiliaria al que se adhiere Cascales y sobre las relaciones estrechas que mantuvo con el grupo privilegiado murciano. Conocidas son las dificultades que los humanistas españoles hubieron de pasar para dedicarse a su teórica tarea específica (la edición y el comentario de libros), agobiados como estaban por la perentoria necesidad de encontrar empleo. Privados de sus aliados naturales por la inexistencia de una burguesía urbana acaudalada, les fue bastante difícil encontrar un mecenas que les brindase protección y que corriese con los gastos de edición de sus libros (22). Cascales tuvo en este aspecto una suerte más que mediana: muy pocas son las obras que en vida le quedaron inéditas. Sin embargo, no fue su mecenas particular el cabildo eclesiástico, con el que mantuvo relaciones frias y tirantes, sino la nobleza murciana la que ejerció tal papel. Primero, Saavedra Fajardo le facilitó los necesarios contactos para publicar las Tablas poéticas. Más tarde, el Ayuntamiento le encargó la redacción de los Discursos históricos y corrió con los gastos de publicación de las Cartas filológicas. Por contra, y confirmando lo que deciamos, el cabildo catedralicio desestimó la posibilidad de publicar la Historia del Colegio de San Fulgencio..., aduciendo la escasez económica(23). Este hecho resulta significativo. Sin perjuicio de que las razones expresadas por los capitulares fuesen ciertas, no podemos olvidar que el cauce prioritario por el que la Iglesia canalizaba las inversiones para el mantenimiento de su prestigio no era precisamente el de publicar libros. Muy diferente hubiera sido la respuesta de hallarse la diócesis inmersa en algún pleito que precisase argumentaciones escritas. Pero es que además, Cascales, humanista (por muy sumiso que su humanismo fuese) y seglar, quedaba desde el punto de partida descalificado en el escalafón social para ser considerado, frente a la aureola que rodeaba a los teólogos o a los juristas, como personaje con suficientes timbres de gloria para dar lustre a la institución eclesiástica. Más fácil resultaba la simbiosis de intereses con el concejo municipal. Algo más diremos sobre esto más adelante, pero señalemos aquí, que fue una institución de predominio nobiliario la que suplió el papel de mecenazgo que debió haber desempeñado la burguesía, prácticamente inexistente. Es un dato muy importante a tener en cuenta para enjuiciar la modulación particular que siguió nuestro humanismo en aquel tiempo. En el caso particular de Cascales, al tiempo que el municipio halló quien le diera lustre y prestigio, el licenciado conseguía congraciarse con la oligarquía local en la que deseaba integrarse. 
Ideologia y pensamiento de Cascales. Las Tablas poéticas y las Cartas filológicas

\section{Clasicismo y moralismo.}

El licenciado, nacido cuando los reinos hispánicos comenzaban a descender la sima de la decadencia, desarrollo su actividad literaria en el período más pleno de la que ha sido denominada cultura del Barroco, la cual define Maravall como "la respuesta, aproximadamente durante el siglo XVII, dada por los grupos activos en una sociedad que ha entrado en dura y difícil crisis, relacionada con fluctuaciones criticas en la economía del mismo periodon (24). Por lo tanto, y sobre este fondo que lo es de crisis general, se desarrollan los caracteres propios de la cultura barroca (urbana, masiva, dirigida, consevadora), que responden a los procesos económicos y sociológicos que vivió la época, estudiados por este mismo autor (25). Junto con factores de otra indole (político-religiosos: Contrarreforma, absolutismo, evolución del humanismo, etc.), la conjunción resultante determinó en gran medida el carácter del humanismo y el papel ejercido por los pensadores durante el Barroco. Desde que el Concilio de Trento subordinó la política y la filosofía a la moral y al dogma, el brillante humanismo español del siglo XVI (prácticamente el erasmismo) quedaba condenado a verse despojado de su fundamental espíritu crítico, y a ser reducido a sus aspectos más superficiales y formalistas. De los muchos Erasmos (el filólogo, el político, el religioso), pervive estrictamente el primero, refugiado y reducido a los gramáticos, simbolizado en el estilo ciceroniano, esteticista y vacuo(26). Este humanismo, "reorientado" de acuerdo con los intereses que encarna la nueva cultura, eludirá las cuestiones conflictivas, religiosas y políticas, cubriéndolas con ropajes de disimulo o, en la mayoría de los casos, no abordándolas. El papel de los intelectuales es, por regla general, el de agentes en la socialización de los valores y pautas de comportamiento que proponen los grupos dominantes. En el caso de Cascales, hallamos un fiel reflejo de la situación expuesta: su actitud beligerante en favor de los intereses del sistema, lejos de ser llevada como una carga, responde a una adhesión íntimamente asumida y defendida.

No obstante lo expuesto, la trayectoria que siguió el humanismo español durante el periodo comprendido entre el eclipsamiento del erasmismo y la aparición de los novatores sigue siendo, en gran medida, una incógnita por desvelar. Bataillon, en un magistral texto, dejó planteadas las cuestiones. Si en el terreno literario la recién descubierta Poética aristotélica, con su doctrina de la doble verdad - la particular de la historia y la universal de la poesía - prestó su apoyo para la doble necesidad de moralidad y racionalidad que experimentaba el clasicismo, éste, desde ciertos puntos de vista, se vio favorecido por el sensible alejamiento del humanismo respecto de la orientación erasmiana. Aparece ahora en la escena un 
humanismo reposado, fundado en el estudio de los poetas y oradores latinos. "Su enseñanza tendía sobre todo a adornar el ingenio, a iniciarlo en el bien decir; no se trataba ya de formar espíritus capaces de confrontar la fe con sus fuentes. La poesía latina clásica salió del semiostracismo a que la habian relegado los humanistas cristianos. El puritanismo (...) cedió el paso a un moralismo atemperado, que no se escandalizaba ya de las fábulas paganas, sino que se contentaba con expurgar a los antiguos de sus obscenidades»(27). Sin mencionar para nada a Cascales, Bataillon parecía estar caracterizándole. El licenciado, en efecto, resulta prototípico en ambos campos, clasicismo y humanismo. Sin embargo, si es clara la orientación moralizadora que preside la obra de Cascales, la cuestión del racionalismo requerirá de las oportunas matizaciones, que haremos más adelante.

Comencemos, pues, por la cuestión del clasicismo. Que Cascales se encuadra en esta tendencia es cuestión al margen de la duda después del estudio de García Berrio sobre las Tablas poéticas(28). Sin adentrarnos en un comentario minucioso, cabe resaltar las conclusiones más interesantes que este estudio nos depara, en tanto que tenemos la convicción de que resultan generalizables al conjunto de la obra cascaliana:

- Escasa originalidad de la obra, inverosímilmente anacrónica. Ajustada a un esquema aristotélico de ninguna novedad, se presenta ante nuestros ojos como un centón de textos bastante mal conectados.

- Orientación didáctica y pragmática que soslaya toda especulación divagatoria.

Ya desde estas dos características se plantea el problema clave en Cascales: la ausencia de sentido crítico, reforzada por una actitud reacia a toda innovación, muy en consonancia con la doctrina clasicista.

Las Tablas - que también recogen la diferenciación de la doble verdad de la poesia y de la historia - contienen, sin embargo, dos novedades que colocan a Cascales en el inicio de dos líneas característicamente barrocas. Se trata de la firme y estable división de los tres géneros poéticos fundamentales (lírico, épico y dramático), y de la primera formulación coherente y seria de una doctrina del concepto literario, "el más extenso y valioso anticipo en España de la Agudeza y arte de ingenio de Baltasar Gracián» (29) . Así pues, clasicismo, conceptismo y afirmación de la poesía lírica son cuestiones que se presentan emparejadas en Cascales. Y si Maravall ha dejado claro que la supuesta incompatibilidad clasicismoBarroco no es tal, sino que "la conservación del ideal grecolatino y la aceptación de la Poética de Aristóteles van juntos en el origen del Barrocos (30), alegando en confirmación de este punto la influencia de Robortello en Lope, no menos ciertos resultan estos supuestos en el caso de Cascales. A nivel general, tenemos ante nuestros ojos a un hombre que junto a una clarísima filiación clasicista (de hecho, las Tablas... constituyen el mejor resumen que existe sobre los tópicos del clasicismo español), muestra 
una no menos evidente mentalidad barroca. De otra, y por descender a los particulares, las fuentes italianas de Cascales (Robortello, Minturno y Tasso) adquieren tal importancia que García Berrio llega a plantearse la posibilidad re una estancia italiana del licenciado(31).

Respecto al conceptismo, y aparte las consideraciones literarias, es evidente su inserción dentro de las coordenadas generales de dirigismo cultural propio del Barroco. Sus teóricos -y Cascales es el primero de ellosno son propiamente filósofos morales, pero sí preceptistas de moral que buscan proyectar su pensamiento sobre las costumbres, lo que les lleva a convertirse en técnicos psicológicos de moral para configurar conductas (32). Este eticismo, derivado de la identificación, a nivel pragmático, conductamoral se convierte en un rasgo dominante en la producción cascaliana. Su orientación le viene dada por el intento de penetrar en el conocimiento del hombre, al menos a nivel superficial, para con la posesión de la historia y de la sociedad servirse de los mecanismos más adecuados que permitan controlar su conducta (lo que implica una visión antropológica pesimista). Moralismo pragmático, pues, sumamente claro en las Cartas filológicas, que ahora vemos perfilado, a nivel de la teoría estética, en las Tablas poéticas. No obstante, hay otro hecho de gran importancia en cuanto a su constatación, con vistas a completar un acercamiento satisfactorio a la obra de Cascales. Estamos hablando de elementos barrocos en el pensamiento del licenciado, y de una postura de fondo igualmente barroca en cuanto que responde a una conciencia de crisis. Pero en modo alguno podemos esperar un grado de definición, en temas concretos, plenamente desarrollado. Tal hecho, que depende de la propia concepción de la filologia, de su saber, que el licenciado tenía, se debe en igual medida a la fortísima presencia del ideal clasicista, responsable de la introducción de un elemento que "fosiliza» teorizaciones más profundas. Por decirlo de algún modo, Cascales es, en el campo de sus teorias, un hombre de "transición", por cuanto su denodado apego al canon clasicista, aristotélico-horaciano, se convierte en una rémora, en un prejuicio, que le coloca en sus ideas en posición de anacronismo respecto de sus contemporáneos. En cualquier caso, sus pensamientos, tal como son expresados en sus obras, son de hecho mucho más barrocos que sus ideales. Esto, que vemos ahora en lo que toca al conceptismo, reaparecerá después en cuestiones tocantes a la política, a la filosofia o a la historia.

La firme defensa de la poesía lírica, que Cascales basa en el argumento de que ésta sí es capaz de "imitar" acciones humanas a través de la licencia de lo verosímil, podemos interpretarla también en el sentido del moralismo, si nos planteamos la cuestión en términos latos: no hay que fijarse en el dato en sí de la defensa de la poesía lírica, sino en el énfasis con que tal defensa se hace. Recordemos que estamos en una época en la que la poesía es "encargada" por unos poderes que reconocen la utilidad del empleo de los 
poetas, y que se sirven de ellos porque son unos útiles agentes para actuar y modular la opinión pública (33). Cascales se prestó reiteradamente al cumplimiento de esta función. Baste mencionar su tarea como organizador de los actos celebrados anualmente en Murcia para conmemorar la festividad de San Fulgencio (parece que incluso llegó a escribir un auto de San Fulgencio)(34). De hecho, todo el primer capítulo de la Historia del Colegio de San Fulgencio... no es más que la narración detallada, admirada y expectante, de uno de los frecuentes montajes masivos y extrarracionales que conocieron las ciudades barrocas: la de la entrada en Murcia de las reliquias de San Fulgencio y de Santa Florentina.

Otro de los tópicos que recogen las Tablas es el que hace referencia a la doble función del arte (delectare-docere). Sin embargo, y volvemos con ello a Maravall (35), ahora la naturaleza intelectualista del docere se ha visto profundamente alterada por un tercer elemento: se trata también de "mover" la voluntad. Sobre el particular, las Tablas fijan una doble diferencia entre tragedia y comedia en atención al fin (limpiar el alma, en la primera, por la misericordia y el miedo; en la segunda, por el pasatiempo y la risa) y a la acción (restringida, respectivamente, a personas ilustres y a gente humilde). Como apuntó Garcia Soriano(36), el héroe de la tragedia debe despertar ("mover") la misericordia en atención a la ejemplaridad, dentro de un contexto en el que la fatalidad, lo ajeno al hombre, deviene el primer resorte de lo trágico. Al eticismo pragmatista se une la concepción profundamente estamentalista del licenciado (en realidad, lo primero responde a la segunda) cuando de la acción se trata:

"...para ser una comedia perfecta, ha de ser acción de gente humilde; y sin Aristóteles lo dice también la razón: porque si el fin de la comedia es limpiar el alma de los vicios por medio del pasatiempo y la risa, los hechos de los principales y nobles caballeros no pueden inducir a risa ¿Pues quién? Los hombres humildes: el truhán, la alcahueta, el mozo, el vegete (sic), el padre taymado (sic) (...) Si un príncipe es burlado, se agria y se ofende (...) la gente baja es la que engendra risa.»(37)

La concepción sociológica de Cascales se ofrece diáfana en este texto. Los dos grandes grupos de la sociedad coetánea quedan aqui proyectados en una abstracción que adquiere su pleno significado cuando se la sitúa históricamente. Sólo la plebe, descalificada estatalmente, carente del "premio" que supone el honor, puede ser objeto de irrisión. Las capas superiores, monopolizadoras de ese honor, quedan apartadas de lo vulgar, de lo cotidiano, y en última instancia reservadas para ejercer el más alto ejemplo de conducta moral (38). Ante la contemplación de los hechos terribles que en las altas esferas acontecen, al pueblo (separado por una barrera cada vez más rígida), sólo le cabe sentir miedo y misericordia. Este es el quid de la cuestión. Ambos sentimientos, ajenos a lo racional, se prevén como resultado de la apli- 
cación de una técnica, la trágica. En el fondo, se responde a una intención integradora: un miedo y una misericordia que lo mismo tienden a que el pueblo se conforme en su baja condición y a no desear otra distinta, que a hacerle sentir admiración por el modo de vida de las capas superiores. Era preciso contar con la masa concentrada en las ciudades, formar su opinión, dirigirla y atraerla hacia el sistema de valores de los estratos privilegiados. A fin de cuentas, la doctrina expuesta en el texto que citamos sí es una teorización del esfuerzo por conservar el orden estamental. Orden que es rigurosamente mantenido: poetas, pintores, literatos, y, aquí, un humanista, empenan su labor en mantener el "decoro" estamental (39). Se ha dicho que Cascales se cuenta entre los más acérrimos adversarios del teatro nacional, encarnado en Lope ${ }^{(40)}$, y que, por la misma razón, resultaba cotradictoria la defensa de las comedias que observamos en las Cartas filológicas (41), sólo explicable por la amistad que le unía a Lope(42). A nuestro juicio, no existe tal contradicción, al menos a nivel profundo. Sabido es que en las polémicas entonces levantadas sobre este particular, fueron los elementos de la nobleza los que insistieron en la licitud y necesidad del teatro, arguyendo sus bondades, de igual modo que también conocemos la función integradora que desempeñó el teatro nacional, surgido precisamente en este siglo XVII. Dada la mentalidad de Cascales, y pese a la rémora que aquí pudo suponerle el clasicismo, tanto da que abogase por la representación de las comedias como que se aferrase a la división teórica propuesta en las Tablas. La frase con la que se avenía a moderar su juicio sobre las, como él las llamaba, "tragicomedias", es elocuente: personas "humildes" y "graves" podrían aparecer juntas en una misma obra, siempre y cuando se mantuviese una estricta separación entre ambas, y que las graves no ocupasen un lugar pincipal en la acción y, por tanto, no despertasen irrisión(43).

\section{Razón e historia.}

El párrafo que hemos hecho objeto de nuestro comentario contenía una alusión a la razón que no es posible obviar. Se trata de la segunda necesidad experimentada por los neoclasicistas, la del racionalismo. Igualmente, indicábamos que debía matizarse qué tipo de racionalismo era éste. En tal sentido, y aunque falta una expresa elaboración teórica sobre el tema en sus obras, Cascales sigue siendo un personaje prototípico. La separación tajante entre la verdad general de la poesía y la particular de la historia, de raíz filosófica, derivaba de la jerarquización medieval de los saberes, que colocaba en la cúspide a la teología y hacía depender a todos los conocimientos, científicos o no, respecto de la filosofía. La historia de la aparición de la ciencia moderna desde el Renacimiento hasta el siglo XIX es precisamente la de la emancipación de aquellos saberes y la de su constitución en ciencias autónomas, adecuadas a un sistema natural. Sin embargo, en este momento del siglo XVII, cuando todavía está lejana la introducción en España del racionalismo cartesiano o del empirismo científico (los dos grandes 
movimientos que salen a la luz entonces), hablar de "racionalismo" sólo tiene sentido si tal término es encuadrado con referencia al marco que ofrecen las concepciones medievales vigentes. En efecto, "cada día aparece mayor la parte de la tradición medieval en los pensadores nuevos desde el Renacimiento hasta el Racionalismo" (44). La separación aludida, a su vez, determinaba dos planos: el de la abstracción (el arte poético), y el de la realidad (la historia).La razón encontraba su ámbito de desenvolvimiento en el primero de ellos, pero ésta debe ser entendida como razón discursiva, propia del aristotelismo medieval y tomista, y en plena consonancia con el estilo ciceroniano descubierto por el clasicismo. Es la misma razón que reaparecerá constantemente utilizada en las Cartas filológicas, eminentemente deductiva. Sus argumentos se basan en la acumulación y contraste de las autoridades en la materia, dispuestos de acuerdo con un criterio en el que lo estilístico tenia gran importancia. En definitiva, una metodología mimética respecto de la silogistica, utilizada por los saberes que por entonces se entendian como ciencias (teología o derecho). Y no está de más recordar que "ciencia" era el conocimiento de causas verdaderas de los hechos que se presencian (45). Las consecuencias de este planteamiento son de diverso tipo. En primer lugar, implicaba negar todo carácter científico a la historia (aunque la poesía no dejaba de ser considerada un arte) (46), por conocer sólo hechos de lo real y no poder elevarse al conocimiento de causas. La teoria de la doble verdad reforzaba tal concepción. Por tanto, la historia queda supeditada a un conocimiento de tipo subsidiario: en tanto que no puede remontarse a conocer verdades generales ni las correlativas causas finales, por sí misma, tales causas quedan fijadas fuera de lo que en puridad hoy denominariamos ámbito natural de la historia. Sin duda, y es la más negativa de las implicaciones, con la introducción de un finalismo extrínseco no hay mejor camino para penetrar el campo histórico de elementos alógenos, reduciendo el papel de la historia al de servir, como una mera herramienta, a principios más generales (éticos o políticos, moralistas o apologéticos).

De ahi que, como veremos, la historia aparezca siempre muy relacionada con la descripción de las costumbres, de los países, etc., disuelta en el contexto más general de la filología. Ciencias como la antropología, la geografía o la propia historia todavia no han alcanzado su emancipación respecto de la concepción filosófico-teológica. Salvo en el terreno de las teorias estéticas (y esto en España sólo en muy escasa medida), el resto de los saberes, y en especial los derivados de la historia, no han podido librarse del peso que representaba el moralismo. El racionalismo, en el fondo, alcanza sólo hasta donde se lo permiten los límites que aquél le establece, y aún frecuentemente se queda un poco antes. De todas las consecuencias negativas, la más relevante es - de nuevo- la pérdida del sentido crítico con el que la razón se presentó emparejada en el erasmismo, y más tarde, ya en plena diferenciación de un saber histórico individualizado, con el criticismo de novatores e ilustrados. Por último, aunque en si tenia un carácter neutro, 
la concepción retórica de la historia no deja de ser un reflejo negativo de todo este esquema. Recordemos, además, que éste a su vez es un reflejo de todos los condicionantes generales en que se desenvuelve el Barroco y que dejábamos esquematizados al comenzar este apartado.

Sin embargo, podemos hablar, en un plano secundario, de consecuencias positivas. Aunque en hombres como Cascales el procedimiento discursivo seguía siendo el aplicable a su campo de trabajo: "el discurso es un tratado donde se disputa con varias, y subtiles causas alguna cosa de qualquier materia que sean(47), separar los dos niveles de verdad y acotar el uso de la razón lógica al plano de las abstracciones ímplicó abrir el camino a la "razón natural" y a la experiencia. Con ello, no sólo se sientan las bases -sólo implícitamente - para un lejano empirismo de base histórica, sino que se coloca a la historia - pese a ser concebida como un conocimiento de lo contingente- en las vías de su constitución como disciplina emancipada, por cuanto esto implicaba en primera instancia un cuestionamiento del planteamiento científico al uso. Incluso en obras como los Discursos históricos, y sólo de facto, Cascales acota el terreno histórico, bien que ampliamente, al conocimiento de los hechos de los hombres, con lo que queda muy apartada una noción de tipo providencialista, Pero no nos engañemos: aunque de modo mediato, la voluntad divina sigue ocupando el telón de fondo. Estamos, pues, dejando constancia de que, en medida muy reducida, Cascales no deja de reflejar ciertos elementos que poco a poco (consecuentemente de un modo todavía muy poco claro) contienen lo que más tarde conformará la historia científica. Pero, y por esto mismo, el licenciado distó mucho de tener conciencia de este hecho (faltaba la perspectiva que hoy poseemos).

Precisamente, en este terreno de la «irracionalidad" de la historia, se nos muestra un ejemplo del trasvase existente entre las doctrinas clasicistas y la visión del pasado. Nos referimos a la importancia que concede en la teoria de la tragedia al fatum ${ }^{(48)}$, que reaparece en multitud de ocasiones en las alusiones de Cascales a su visión de la historia. Lo mismo podríamos decir en cuanto al procedimiento discursivo. $Y$ si la fatalidad es un elemento clave en la cosmovisión barroca, creemos que, a la luz de cuanto llevamos expuesto, el clasicismo fue una doctrina que se adecuó perfectamente a las necesidades de esa cultura.

\section{3. ${ }^{\circ}$ El humanismo de las Cartas filológicas.}

Ninguna obra como las Cartas filológicas para comprobar cómo estos temas se desarrollan en Cascales. Sin duda, el carácter de miscelánea que las singulariza ofrece el más rico elenco de materias sobre las que se despliega su pensamiento. García Soriano(49) las clasificó en distintos grupos temáticos: polémica y crítica literaria, erudición humanística, curiosidades y costumbres coetáneas, eutrapelias o pruebas de ingenio, cartas político-morales, históricas y genealógicas, y epigramas. Tal ordenación, 
excesivamente compartimentada, debe ser manejada cautamente, por cuanto corremos el riesgo de perder la siempre deseable visión de conjunto. Previo a nuestro análisis - siempre somero- resulta necesario efectuar algunas consideraciones de índole general.

Por su misma heterogeneidad, las Cartas no se presentan con la unidad que ofrecería un tratado específico sobre un tema concreto. Cascales, que no puede ser tenido propiamente por lo que diriamos un pensador, tampoco da muestras de un interés específico por temas que se apartasen de su oficio de gramático (filologia-historia). En el prólogo Al lector, que precede a las Cartas..., reconoce explícitamente que de los distintos géneros epistolares, "las que pertenecen a la filologia son materia propia (sic) de las mias", desechando las de tipo teológico o filosófico(50). El término filologia aqui no se emplea en el sentido que hoy entendemos. El licenciado coincidia en compartir la acepción común entre los humanistas de la época: la filologia (la gramática latina sobre todo) era la herramienta que permitía el acceso al acervo cultural del pasado clásico, entendiendo éste no como un ciclo cultural cerrado, sino como una herencia aún viva. Como en tantas otras cosas, Cascales da muestra en esto de la escasa originalidad de sus planteamientos (dificilmente podía ser de otro modo). Tal es el principal interés que ofrece, como reflejo de la situación general a la que había llegado nuestro humanismo en ese momento. Seria tarea vana buscar en él una actitud aperturista a la innovación. Planteamiento que tiene su razón de ser en su misma conciencia, tan pegada a la veneración por la autoridad de los clásicos (nunca juzgados desde una perspectiva crítica) como deliberadamente intransigente a admitir desde sus cánones los elementos nuevos que se estaban desarrollando (ahí está su polémica con Góngora, que paradójicamente le colocaba en la línea conceptista sin proponérselo). Además, hablar de filologia en este momento significa, como veíamos, restringir el interés a las cuestiones puramente formales o al moralismo ejemplarista. Sólo en este sentido puede ser entendida la utilización que hace de las fuentes. Abrumadoramente ricas (ya indicó Bataillon que no había reparos en revivir las obras paganas), necesitan desde luego un análisis profundo que las jerarquice y que todavía está por hacer. Por el momento, nosotros lo omitiremos para centrarnos en una simple aproximación orientativa.

La mayor parte la llevan los autores de la clasicidad latina, entre los que no falta casi ninguno: Ausonio, César, Catón, Cátulo, Cicerón, Estacio, Floro, Horacio, Juvenal, Lactancio, Lucano, Marcial, Mela, Ovidio, Petronio, Plauto, Plinio, Quintiliano, Séneca, Suetonio, Tácito, Tito Livio, Terencio, Virgilio... Los griegos ocupan un lugar secundario (exceptuando el papel principalisimo de Aristóteles), puesto que Cascales desconocía esa lengua. No faltan, por supuesto, los Santos Padres, elemento de contraste respecto de la Antigüedad pagana y filtro en el juicio moral sobre ella, como tampoco los humanistas italianos, franceses y belgas de los dos últimos siglos. 
Sin embargo, escasean las referencias a los autores españoles, a quienes no se recurre con la admiración sentida hacia los extranjeros, y contra quienes, usualmente, se polemiza: contradictoria faceta del nacionalismo latente en Cascales.

Desde luego, se advierte una cierta liberalidad en este uso de las fuentes. Hombres como Lipsio (colocado como modelo a seguir)(51), Scaliger, Boulenger, Pithou, Moreto, (52) o Arias Montano(53), que son citados con reiteración, y a los que venera como grandes humanistas, mantuvieron vivo el espiritu crítico que prolongaba el evangelismo erasmiano. Más tarde, los primeros reformistas ilustrados se vieron forzados a ocultar su pensamiento bajo la apariencia de culto a los clásicos(54). Sin embargo, un abismo separa la actitud de Cascales respecto de la de aquellos espiritus criticos. Nada más revelador que constatar las ausencias: ninguna mención dedicada a los problemas religiosos, ni el más mínimo planteamiento de cuestiones tocantes a la crítica textual. Su carácter, sus condicionantes biográficos y la postura que consecuentemente sostuvo ante el mundo y la sociedad, le apartaban de cuestiones como las referidas que, en aquel tiempo, conducian casi siempre a chocar contra los pilares del sistema social establecido. Su humanismo, desprovisto de todo ribete de heterodoxia, que entonces era preciso alejar a toda costa, y más en un hombre de su origen, giraba en torno a esa concepción esteticista y moralizadora de la que ya hemos hablado. Reafirmémoslo, Cascales es un hombre del Barroco que hereda y refleja, como un notario, la situación de un humanismo que habia quedado confinado al estrecho margen de los gramáticos, sumiso y pacato, y que da curso a los temas de acuerdo con las nuevas orientaciones que venian prefijadas por aquella cultura. Si ya es significativo que el autor español más citado sea Martín Antonio del Río(56), lo es mucho más su propia idea del humanismo, diáfanamente expresada en algunos pasajes de las Cartas...:

«El oficio del gramático (...) es la ciencia de hablar y explicación de los autores (...) Cicerón, en el lib. I De Oratore, dice que al gramático le pertenecen cuatro cosas: comentar los poetas, dar noticia de las historias, interpretar las palabras y enseñar el tono de la pronunciación (...) Si el poeta abraza tantas noticias de cosas, el gramático que ha de explicar lo que él apuntó concisamente (...) ¿qué cornucopia, qué cosecha de cosas habrá menester para cumplir su oficio? (...)

En segundo lugar entra en el conocimiento de las historias sagradas y humanas, los ritos y costumbres de las naciones, los acontecimientos varios de los reinos (...) su juicio ha de dar sobre la historia; si el historiador guardó el estilo histórico verdadero o no; si observó las leyes de la historia (...) si concordó los tiempos (...) la historia es una verdadera narración de las cosas pasadas (...) el fin de la historia es la utilidad pública, nacida del escarmiento ajeno (...) la historia no debe hacer caso de los acontecimientos humildes y bajos (sino de los ilustres)" (56). 
Lo primero que destaca en esta definición (cuyo comentario, si queremos, es todo este artículo) es precisamente esa contemplación de la herencia clásica como un legado pseudo-vivo. Pero es mucho más interesante que el término humanismo se omita y deje paso al de "gramático»: no faltaba sentido de la realidad en Cascales (de hecho, sólo llama humanistas a aquellas grandes figuras que citábamos). $Y$ aunque haya una reivindicación del papel de la gramática como janua scientiarum que puede poner en entredicho la posición de los encumbrados teblogos, juristas y médicos, se ve en todo ello el reconocimiento de la humilde misión que correspondía a quienes la ejercian. En suma, una visión que mira hacia atrás, que reivindica el papel - perdido- que tuvieron en la mítica Edad Clásica, pero que no consigue librarse de los planteamientos tradicionales que orientaban esta disciplina. Ahi están las críticas contra los teólogos y los juristas:

"No os puedo negar que la gramática ha estado siempre por los indoctos en bajo predicamento" (57).

"Que (...) un médico, (...) un teólogo (...) un jurisconsulto (...) hombres que han frecuentado universidades, han arrastrado manteos, han recibido grados y laures (...) tropiecen a menudo en estas niñerias (las faltas ortográficas)" (58).

Acusaciones que llegan a extremos fuertes en la epístola ll de la Década I, donde afirma que «solos el médico y el abogado podían matar libres de pena» (59). De paso señalaremos que las críticas han tenido que ser disfrazadas bajo la fórmula enrevesada, barroca, que supone la eutrapelia o prueba de ingenio. Precisamente este grupo de cartas ha sido tomado en muy poca consideración por los biógrafos de Cascales. En fin, todas estas invectivas lo que transcriben es la tensión característica del Barroco, el descontento social, individual y general, de la época: hay que arreglar las cosas, devolverlas a su sitio. No se propugna una reforma profunda (como ocurrirá en el siglo XVIII), acompañada paralelamente, de una nueva concepción científica crítica. Al contrario, desde la perspectiva de Cascales se trata sobre todo de devolver las cosas al estado en que debieron estar siempre. (Si se nos perdona el símil, este encauzamiento del descontento nos recuerda mucho la cosmovisión típica en los bandoleros del Antiguo Régimen). Naturalmente, que el método y el modo de entender los saberes será la prolongación de este esquema arcaista.

Resulta arriesgado pretender establecer un esquema general, válido para el conjunto de las Cartas..., del método que sigue Cascales. A grandes trazos, podemos decir que se corresponde con el que ya hemos descrito más arriba, discursivo, basado en argumentos de autoridad, falto de criticismo y formalista. Asi pues, la sumisión al principio de autoridad (sólo se polemiza con los contemporáneos) coagula cualquier orientación hacia la crítica textual; la razón deductiva (cuando se utiliza) coarta toda elaboración empírica. 
El causalismo final facilita la introducción en el terreno antropológico del moralismo o la apología... Sin abandonar nunca el formalismo, sólo en las cartas de tipo político-moral y en las eutrapelias se introducen datos que pudiéramos denominar "empíricos". En fin, un método que, tan buenos resultados podia producir en el campo literario (de ahí que sean estas epístolas las que capitalicen el interés de los ilustrados), como negativos en otros terrenos.

Sobre el telón de fondo de los resabios medievales se despliegan los temas propios del humanismo. Como una constante, el problema principal sigue siendo el que plantea la ausencia de una metodología crítica, y el carácter que revistió esta tendencia desde la derrota del erasmismo y el triunfo de la Contrarreforma. Es la época en la que triunfa la virtus litterata jesuítica, a cuyo modelo se acercan los humanistas. Todo se tiñe del interés por formar a los hombres prioritariamente en la "virtud", y sólo después en la "ciencia".

En el caso de Cascales, hablar de erasmismo es algo que carece de sentido. Algunas de las cartas se ocupan de temas que aquel movimiento hizo suyos, pero son tratados de forma distinta. Después de todo, Cascales era un humanista, y a las preocupaciones generales de la tendencia se debía. Pero el erasmismo ha sido condenado a las profundidades subterráneas. El licenciado, que cita a Erasmo una sola vez y con extrema frialdad, declara que las Cartas... quedan totalmente apartadas del tipo de género epistolar practicado por el roterodamense ${ }^{(60)}$. Lo mismo comprobamos en algunas de ellas cuyos títulos podrían inducirnos a pensar en resurgencias erasmistas. Así, la que trata sobre el lenguaje que se requiere en el púlpito entre los predicadores(61) o la Instrucción para las doncellas que han de ser casadas (62). En la primera es imposible hallar un acercamiento profundo al mensaje de la predicación (a cuyo contenido o "fondo" casi no se hace referencia), puesto que el interés radica en censurar el estilo culterano que se va introduciendo en la concionatoria, basándose en criterios clasicistas. En lo que toca a la segunda, se aborda el tema de modo totalmente distinto al que siguieron un Luis Vives o un Fray Luis de León. Sobre la inevitable fundamentación cristiana, el asunto es de nuevo enfocado desde la perspectiva exteriorista, en la que importa sobre todo la conducta moral en relación con la posición social que se le asigna a la mujer. Si, por supuesto, la primera condición es la de ser buena cristiana, ese cristianismo tiene su manifestación sobre todo en la conducta: «ejercitese en actos de caridad, sea muy devota, sea muy aficionada a los pobres (...) hágase a los ayunos que manda la Iglesia; aúne las prácticas y sermones y aprovéchese de ellos; tenga sus horas diputadas para rezar; y no sea escrupulosa ni libre (...), frecuente la confesión, frecuente las devociones, y todo esto bajo la obediencia de sus padres»(63). De hecho es la cita más extensa con que contamos para conocer lo que para Cascales sería un modelo de cristianismo. Sin duda, un modelo perfectamente normalizado, nada sospechoso de espíritu interiorista. El res- 
to de esta carta es una mera descripción de cuáles han de ser las costumbres ejemplares que corresponden a una mujer casada. Por lo demás, la cosa se ve agravada porque se está tratando de mujeres. Ciertamente, el licenciado fue ponderado en esta ocasión, a causa del respeto debido a su corresponsal. En otras, expresa opiniones de furibunda misoginia, muy en consonancia con su ideología. Un simple botón de muestra: «las mujeres (...) sus desdenes (...) sus caricias falsas (...) sus embustes (...); en fin, gente con más vueltas que espada genovesa y que turbante armenion (64).

En otro orden de cosas, que Cascales escriba la casi totalidad de sus obras en castellano, o que cuando introduce un párrafo latino lo traduzca casi invariablemente a continuación, nos confirma en la tesis de que su figura resulta paradigmática en el terreno, también, del humanismo.

Asi pues, y si Bataillon anotó que la difusión del neoestoicismo contribuyó en España a prolongar y, al mismo tiempo, a borrar el erasmismo(65), ¿podemos hablar de neoestoicismo en Cascales? La respuesta a esta pregunta, por las razones de índole general que se apuntaron, resulta difícil. El enciclopédico acopio de fuentes unido al escaso interés por las especula. ciones filosóficas, por otra parte, contribuyen a difuminar su pensamiento sobre este particular. No obstante, ciertos indicios tienden a confirmar la presencia de una cierta veta neoestoica, nunca perfilada claramente, o mejor dicho, nunca confesada de viva voz. En primer lugar, constatemos en Cascales esa visión pesimista del hombre y del mundo, tan barroca, y que le sitúa dentro de las coordenadas generales comunes a los pensadores neoestoicos. En este sentido, la lectura de los prólogos a algunas de sus obras (como los Discursos históricos o la Historia del Colegio...) resulta interesante. En ellos, Cascales adopta invariablemente una actitud defensiva ante las críticas que pueden sufrir sus obras para terminar refugiándose en una cierta imperturbabilidad del ánimo:

"No hay cosa totalmente consumada; quanto mas, que a la obra mas bien perfecta se atreve a derramar su mortífero veneno el Momo de la perniciosa embidia. No dexo de tener un honrado miedo, pero no tanto que me dexe caer a los pies del malicioso juicio humano. Ya sé, que ha de encontrar mi libro con cinco géneros de hombres, escrupulosos, malignos, benignos, doctos, idiotas (...) más vale ser vituperado de los buenos, que alabado de los malos (...) Si (...) diere en las manos de los hombres idiotas (...) paciencia y callar (...) cuyo juicio ni me da pena, ni gloria.... (65 bis).

Clarificador resulta igualmente el matiz introducido en el prólogo a la Historia del Colegio..., al ejecutarlo sobre una cita, no de un estoico, sino de un cínico como Antístenes, si consideramos que el cinismo es precisamente una filosofía que surgió en una época de crisis, como lo fue el Barroco. 
En abono de este problemático neoestoicismo podemos también aducir el frecuente recurso a los autores de tal movimiento: Epícteto, Séneca (muy destacadamente), Tácito y Cicerón. Por último ahí está la admiración que siente por Justo Lipsio, que comparte con sus corresponsales Tamayo de Vargas, Carrillo Sotomayor y Lope de Vega.

Pero, sobre todo,lo que realmente subyace -y lo que expresan- en los párrafos citados (hay otros muchos), es la mentalidad conflictiva de un hombre barroco.Pocas cartas como las eutrapelias (66) evidencian con tanta claridad esa conciencia conflictiva. Tras elegir un tema aparentemente banal (hablar de los Bermejos o de los eunucos) o sorprendente (contra las letras...), y respetando el método discursivo, plantea la cuestión y la lleva hasta extremos absurdos. Esto, que siempre queda justificado bajo el pretexto de que se trataba de pura y simple diversión, equivale, como advertíamos, a poner de facto en tela de juicio la propia metodologia, aunque difícilmente fuese esa la intención perseguida. Primariamente, estas cartas - provistas de un indudable gracejo y fina ironia - son una vía para dar escape a tensiones latentes. Por tanto, nada más natural que contengan elementos autobiográficos: en la carta que trata de los Bermejos «he desfogado mi cóleran - dice-por problemas ocasionados al comprar una casa; en la de los dos capones cantores introduce un párrafo tan significativo como éste, ahora que conocemos la circunstancia de su origen: "ni dejaría de ser linaje ilustre el que, estando lleno de títulos y caballeros nobilísimos, tuviese algún descendiente defectuoso por algún casamiento innoble»(67). $\mathrm{Pe}-$ ro la de mayor interés por sus trascendentes implicaciones es la que escribió Contra las letras... Con ella, nos acercamos al núcleo ideológico central en Cascales, cuya preocupación fundamental sabemos que es la justificación de la nobleza (y si se nos apura más, diremos que del grupo privilegiado murciano).

Ahora bien, antes de pasar a ocuparnos de lo expuesto en esta carta y en las con ella relacionadas (las político-morales), dejemos constancia de que el recurso a la historia se hace de modos distintos en el licenciado, modos que responden a una intencionalidad común y que separamos aquí en aras a la claridad expositiva. Mientras que en algunas de las cartas la historia es considerada como el objeto central, en otras, desempeña más bien la función de "banco de datos" sobre el que apoyar la enunciación de unos planteamientos político-morales. Efectivamente, y aunque se conserve en todos los casos la preocupación por guardar un "estilo propio", elegante, no es el mismo papel el que tiene la historia en una carta como la que se ocupa del nombre "Tajo y otras cosas..., o la que trata de los Delgadillos, Manueles..." (68), que pudiéramos denominar especificamente históricas, que el ocupado en otras como las que tratan de los baños y termas de los romanos, sobre las ceremonias del casamiento gentilico, sobre la cria y trato de la seda, y otras por el estilo, en las que en mayor o menor medida introduce 
elementos de su propia experiencia(69). Por último, un tercer grupo es el constituido por las upoliticas»(70), en las que habla con insistencia de la necesidad para el buen gobierno de recurrir «a la razón natural y a la experiencian. La misma variedad de las cartas la justifica el licenciado en cuanto que "la filologia tiene los brazos muy largos; pues se pasea por el campo de todas las ciencias y todas las artes, no ya con aquella perfección que cada una pide, pero a lo menos chupando (...) 10 más dulce de las floridas plantas"(71).

Sin duda, las más interesantes son estas últimas cartas, que decíamos relacionadas con la eutrapelia contra las letras... Comienza ésta, pues, con la contraposición de las letras - el artificio humano- y el orden de lo natural. El cultivo de las letras que hace sufrir penurias de todo tipo a su estudioso:

"... impide muchas veces los piadosos oficios de la virtud, roba y nos quita las horas de recreo (...) ¿Qué cosa más contraria a la Naturaleza, la cual nos dio la lengua para el uso de hablar, y nosotros la metemos en la vaina del silencio y damos sus oficios a las manos, al papel, a la pluma? (...) Como si la madre Naturaleza no fuera guia (...) como si la verdad evangélica no se hubiera extendido y sembrado por toda la Tierra (...). Antes de los inventores de las letras, infinitos vivieron vida santa, pía y ejemplar; infinitos gobernaron repúblicas y reinos con sola su buena inclinación y costumbres, acompanadas del dictamen natural y discurso de la razón y con la experiencia de varios acontecimientosw (72).

Más tarde, utilizará un párrafo de Séneca para confirmar su planteamiento, de que las letras llegan a impedir a quienes las cultivan el desrrollo de las virtudes naturales. Una visión que se prolonga y esclarece en un pasaje de otra carta:

"El rey Agasicles, siendo mancebo, y queriendo el reino darle maestro, dijo: Yo quiero ser discípulo de aquellos de quien soy hijo; significando que los príncipes y caballeros ilustres más se mueven con los hechos de sus antecesores que con la doctrina de los grandes maestros"(73).

El paralelismo de planteamientos entre los textos de Cascales y la "República literaria" de Saavedra Fajardo(74), es más que sorprendente, tanto como inverosímil puede parecer que dos hombres tan cultos como ellos denosten - aunque sea por vía de ficción - las letras hasta tal punto. Luis Gil, al ocuparse de la obra de Saavedra Fajardo, indicaba: "proyectada la caricatura del ensueño literario en las circunstancias históricas de la monarquía española a comienzos del siglo XVII, lo que esta ficción viene en el fondo a plantear es el problema de la tolerancia y sus imbricaciones 
culturales. Y la respuesta viene dada desde la ideología dominante, de modo consecuente con los intereses de la dinastía austriaca obligada a ejercer de gendarme de la ortodoxia european (75). El ejercicio de la actividad pensante, llevado al extremo, podía provocar el caos de la inoperatividad cuando llegase el momento de tomar una decisión práctica y rápida. Pero es preciso observar una diferencia de matiz entre ambos. A Saavedra lo que le interesa es la educación del Príncipe; Cascales, de miras más cortas, siempre dirige sus consejos políticos a nobles concretos que se los han solicitado. No obstante, el fondo de la cuestión es el mismo y gira en torno al tópico de la virtud: utilizado en distintos sentidos (ya lo veremos), aquí su papel es el de poner precisamente el justo freno ("el justo medio", de un clasicista), al ejercicio de la actividad racional del hombre, encauzándola y evitando que alcance extremos amenazadores para la consevación del sistema. Desgraciadamente, no conocemos la fecha de redacción de la carta cascaliana, si bien sabemos que la de Saavedra es una obra temprana (1612); por lo que sería lógico pensar que es este último quien influenció sobre el primero. Sin embargo, y mientras no se investigue profundamente este punto, sugerimos la posibilidad a comprobar de que sea lo inverso, que Cascales (un hombre de "transición») transmita el planteamiento a Saavedra(75 bis).

La razón natural y la experiencia de que habla el licenciado, ¿podria hacernos pensar en un planteamiento de tipo empirista? Como en tantos otros puntos, aqui tampoco es fácil encontrar una postura conscientemente definida. La razón natural no es más que la derivada de la aplicación de la humana facultad de pensar sobre el terreno de lo real; la experiencia es un término que está siendo utilizado, sobre todo en un sentido sapiencial, más que científico. Sin temor a equivocarnos, podemos decir que Cascales hace una aproximación empírica al problema del gobierno político, pero incluso por la propia restricción de sus consejos sobre la materia a nobles, y no al príncipe, no hay una sistematización sobre ese saber empirico hasta el punto de poder considerarlo una "ciencia política".

Cascales, que también aquí se queda a medias (aunque es el terreno en el que más avanza), tanto no alcanza ese empirismo ya casi científico, como se encuentra lejos de un moralismo racionalista, trasnochado e inoperante. La propia utilización de la historia como banco de datos, aunque es difícil matizar, muestra ese mismo empirismo. He aquí un texto sobre esta materia:

"El General tenga consejo con los capitanes (...) hombres de experiencia y buen entendimiento (...) proponga el caso (...) y ejecute lo que le parece mejor. Si no hay peligro en la dilación es más acertado hacer una, dos y tres veces consejo, hasta deliberar lo que importe al servicio de Dios y el rey" ${ }^{(76)}$. 
No se puede negar la presencia de un pragmatismo muy cercano al empirismo, pero no se da ni una profunda preocupación por el asunto, ni una teorización extensa, ni una auténtica sistematización metódica. Hay todavia un fondo tradicional, sapiencial, detrás-de todo el planteamiento de Cascales $(77)$.

\section{Teoría de la nobleza.}

Pero el problema, que referimos arriba, no es más que una parte de la que es auténtica preocupación en la mente del licenciado por revitalizar el papel y los ideales nobiliarios. Las páginas dedicadas a este tema son numerosas. Como escribe Maravall(78), es sabido que uen los siglos modernos, bajo el régimen de Estado que forman las grandes monarquias, las aristocracias tradicionales perdieron el monopolio de la función militar y abandonaron con ello su propia razón de ser como estamento". Esta desnaturalización que abrió fisuras en el papel y en el prestigio de la nobleza produjo tanto críticas agrias, como una reacción en la que el elemento alto se impuso, conservando su posición de clase, adaptada a otras funciones. "En efecto, de defensores del pueblo, conforme a la doctrina tripartita medieval, veremos ahora a los nobles convertidos en mantenedores del orden monárquico señorial" (...) subsite, por mucho tiempo, el papel de "espejo", de paradigma que se reconoce al noble en cuanto tal y según un modelo que se supone repiten cuantos individuos integran el grupo. Es el "modo de vida conforme al honor" respecto al que otros sectores distinguidos por vías diferentes -el saber, la riqueza - intentarán no destruirlo, sino participar en élı) (79).

A lo largo de este trabajo hemos visto cuáles eran las razones que motivaron la aproximación de Cascales a la nobleza y hemos adelantado que puso su pluma al servicio de este estamento. La producción realizada en este sentido, de la que las Cartas filológicas contienen parte sustancial, tiene su cima en un pequeño tratado sobre la cuestión inserto en sus Discursos históricos ${ }^{(80)}$. Aunque las Cartas son posteriores, en ellas estamos ahora. Algunas, como las que tratan de la cría y trato de la seda y acerca de las viñas y bodegas( ${ }^{(81)}$, lo que evidencian es esa radical identificación personal del licenciado con el modo de vida nobiliario. En la primera, tras cantar las excelencias del cultivo de la seda (un timbre de gloria para una Murcia en la que los grupos privilegiados poseían la casi totalidad de la propiedad agraria en la que ésta se cultivaba), critica - siempre un juicio moral - el uso de la misma: "que la sencillez de nuestros antepasados era tanta (...) y los ánimos tan ajenos de gustos y superfluidades, que no admitieron, no les pasó por el pensamiento admitir, tan vicioso traje y tan indigno de su honesta severidad»(82). Resulta interesante contraponerla con la carta inmediatamente posterior, en la que el licenciado se propone probar que la cosecha del vino es mayor y más importante que la de la seda 
(acaba de comprarse una viña). La vid, un cultivo más en consonancia con su mentalidad, se ve elevada a través de varias argumentaciones -económicas, médicas, sagradas - a un plano superior: los conocimientos al servicio de una ideología. La carta sobre el uso de los coches conecta de modo directo con estas dos. Tal uso sólo lo considera justificable en caso de necesidad física o, sobre todo, por razón del estado social que se tenga (necesariamente elevado), para poder cumplir adecuadamente la función de ese estado. Lo que no sea esto, es juzgado, desde sus patrones morales, como "ruina de la patria»(83). $Y$ no digamos que las principales causantes de la degeneración en el uso de los coches y de los trajes de seda son, cómo no, las mujeres. En suma, se trata de esa reacción que lejos de querer cambiar el sistema social, pretende restituirle a su hipotética pureza.

La imagen paradigmática del noble y de su papel social resulta clara en la Carta a un caballero salido de los estudios, que está en duda si irá a la guerra o se quedará en su tierra a servir su oficio de regidor(84), en la que Cascales perfila cuál ha de ser el curso que idealmente debe seguir la trayectoria vital de un noble: La milicia y el gobierno son ulas dos templadas zonas por donde caminan los nobles. Tomad el que quisiéredes, que en ambos podéis ser de honra y provecho a vos, a vuestra patria, a vuestro reino, a vuestro rey $y$, lo que es más, a vuestro Dios»(85). Lo deseable -indica Cascales - es que de joven se dedique a la milicia, donde se formará en la virtud y en la austeridad y en la que adquirirá ese «saber de vida" que después le será necesario cuando, ya entrado en canas, regrese a su patria (el lugar donde el hombre nace o se cría) para ejercer un cargo concejil. Como gobernante, amén de evitar la ociosidad, madre de todo vicio, deberá ser buen cristiano y tener recta conciencia (la moral como freno para las conductas de los gobernantes), cuya ley obliga al regidor a ser padre de la patria imaginando que todos los ciudadanos son sus hijos y creyendo que los ha de alimentar. Es el paternalismo característico, que junto con el papel ejemplarizante, se le atribuye al noble en una ordenación social cuyo origen y jerarquización se reputan en la misma voluntad divina.

Pero ningún texto como el Discurso de la Nobleza para conocer el pensamiento del licenciado sobre este particular. Una advertencia previa hemos de realizar. Siendo éste el núcleo central en la concepción ideológica de Cascales, en ningún otro tema muestran sus elaboraciones tan escasa originalidad. Es tan extraordinario el parecido observable entre sus planteamientos y los que hacen los autores en los que se basó Maravall para realizar el estudio a que estamos haciendo referencia(86), que precisamente a fin de resaltar ese carácter básico, por nuestra parte nos hemos ceñido también al esquema seguido por dicho autor, lo que en gran parte nos hace obviar muchos comentarios que no nos pertenecerían. Por lo 
demás, este acoplamiento no ha sido forzado; antes al contrario, aparecen plagios literales y extensos de obras como la de Antonio de Torquemada (Diálogos de la vida del soldado), citada por Maravall. La tendencia a plagiar es una costumbre natural en Cascales, demostrada por García Berrio con respecto a las Tablas, y que ya vimos.

El tema central de este Discurso sobre la nobleza lo constituye el de la virtud. En el sistema de la sociedad estamental, la sangre contaba como vehículo transmisor intergeneracional de una pretendida superioridad de virtudes, como vía por la que llegaba a los señalados en la sociedad civil el designio divino(87). Esta concepción del origen divino, gratuitamente afirmada, desde los siglos XVI y XVII va a ser puesta en tela de juicio. La sangre recibida, por la propia naturaleza del hombre, es en todos ellos la misma. Por tanto, el vínculo pasa a situarse en la obligación, en el sentimiento que la educación y las costumbres crean, de que el "bueno" está obligado a comportarse de manera que no decaiga el ejemplo recibido(88). La opinión de Maravall en el sentido de que era la misma nobleza y algunos escritores a su servicio que pretendían restaurar, y no romper, un mejor orden moral y social, quienes intentaban renovar la fosilizada creencia en la virtud, con vistas a reforzar el papel de ésta en el sistema haciendo pasar el linaje a un papel secundario y derivado, se confirma con total plenitud en Cascales.

En primer lugar, aparece el origen divino de la ordenación del mundo, lo que confiere la lógica inmutabilidad a la sociedad estamental coetánea: basada en designio providencial, la división social existe desde el principio de los tiempos y responde a la necesaria diferenciación de funciones: "si todos fuéredes Reyes, a quién mandáredes? si todos Cavalleros, a quién defendiérades? si todos labradores, y oficiales, a quién vendiérades vuestros frutos? (...) Todas estas diferencias, y otras son menester en el mundo, y nadie por ello se debe tener agraviado" (89).

¿Cuál, pues, es la función de la nobleza, qué es un noble? Cascales refleja en este punto una dualidad: "La nobleza es una dignidad de linage (sic) en que resplandecen virtudes a la vida común, saludables y provechosas. $Y$ aunque esto es propio de todas las virtudes, que a cualquiera que las tenga le hacen Noble, e llustre; pero más particularmente es de aquellas que miran al bien común, ayudándonos en la guerra con virtudes de ánimo, y en la paz con buenos consejos, y con la observancia de la Justician(90).

De la contemplación de ambos textos se deduce el esquema básico en el pensamiento cascaliano sobre la materia(91). Fijar en los designios divinos la ordenación social implicaba el reconocimiento de la tesis tradicional según la cual, la propia nobleza, siquiera con cierta mediatez, tenía ese mismo origen. Sus miembros, colocados en el plano social más elevado, "lucen desde el alto candelero de su estado»(92), por cuyo origen se 
deben a una serie de funciones que han de cumplir determinadas por su status: la militar y la de gobierno. Aquella dualidad entre los dos tipos de nobleza queda inmediatamente aclarada por Cascales, en el sentido de que realmente sólo lo son quienes sirven al gobierno a o la guerra los verdaderamente nobles ${ }^{(93)}$.

Sobre la inmutable partición estamental, dentro de un planteamiento típico del Barroco, hace su aparición el hombre y el tema de la fortuna, como elemento extrarracional que determina el discurrir de la existencia(94), cuya actuación caracteriza Cascales con el párrafo latino: "Si fortuna volet fies de consule rhetor, si volet haec eadem fies de rhetore consuly(95), lo que además viene a reflejar el carácter no totalmente cerrado de la sociedad estamental. En una época en la que, no obstante, van a cerrarse sistemáticamente los caminos de acceso a la capa social privilegiada, no deja de resultar irónica la frase de Cascales: "Señores, los que sois Nobles (...) no despreciéis de ninguna manera a los humildes, y pobres, y al contrario los humildes, y pobres no perdáis el ánimo, ni estéis desconsolados, que algún día os amacenerá alegre, y dichoson (96). Realmente, a los pobres sólo les cabía consolarse.

Esta circunstancialidad queda proyectada sobre el pasado igualmente. Los primeros nobles eran hombres heroicos y virtuosos, y por ello ganaron precisamente tal posición(97). La excelencia de los progenitores se entiende que determinaba una descendencia con iguales caracteres: "No hay que dudar, sino que de los bien nacidos, no solamente no se han de presumir cosas infames, y ruines; pero que se debe esperar la pública salud, la defensa de la patria (...) La bondad del padre resplandece en los hijosn.(98).

El corolario lógico es que cuanto más antiguo sea el linaje, mayor será su pureza, y en consecuencia, más grande su excelencia: “De la antigüedad recibe el linaje grandísimo lustre y valor (99). El noble, por tanto, aparte de las obligaciones que contrae para con la sociedad (defenderla, regirla, dar ejemplo), se debe igualmente a las de su propia condición, intimamente correlacionadas entre sí: ejercer los oficios, conservar la riqueza, sustentar el honor, para, últimamente, "tener en pie el linage» (100). La riqueza juega aquí un papel fundamental(101). Dotada de un sentido extraeconómico, era una manifestación de poder y prepotencia, y su grado determinaba estrictamente el grado de nobleza(102) y su pérdida puede llegar a producir el "acabamiento" de aquélla(103). Sin embargo, no debe ser entendida esta cuestión desde una óptica individualizada. La mayor o menor posesión de bienes es un atributo de la posesión en la que se está (es significativa la división en ricos hombres, caballeros, escuderos e hidalgos)(104), y no a la inversa (la riqueza no produce necesariamente la calidad de noble). No obstante, si perder la riqueza puede comportar en un plazo más o menos largo la pérdida de la condición nobiliaria(105), no sucede lo 
mismo en el caso de conductas desviadas: un noble puede dedicarse al bandolerismo, pero nunca dejará de ser para sus compañeros de cuadrilla un hombre generoso y leal defensor(106).

Aquí es donde pone Cascales su especial énfasis, y por ello el recurso a la virtud. La sangre, vehículo transmisor de la nobleza y que excluye de ella a los ricos que no la poseen (salvo intervención regia, como fons honorum) (107), no basta: "La nobleza de sangre acompañada de la virtud es la verdadera nobleza (...) es la nobleza sola como los ceros en la Arismética (sic), que solos no valen nada, mas acompañados de los números valen infinito" (108). Y a partir de aquí, Cascales propone todo el ideal de vida que piensa corresponde a un noble. Movido por la amenaza que se cierne sobre los pilares del estamento (que más o menos conscientemente refleja este Discurso), al que se siente pertenecer, saca a colación el tópico de la virtud y se esfuerza en dar a los nobles unos consejos y un modo de vida que reconoce principios ya trasnochados en aquellos momentos y que refuerzan, desde la teorización, su función social como grupo útil y necesario.

\section{Con/usión: el planteamiento historiográfico de Cascales}

Llegamos con ello al final del presente estudio. Como conclusión, queremos únicamente señalar que todo el cúmulo de componentes presentes en la mentalidad de Cascales que hemos visto anteriormente se prolonga de manera natural en las grandes líneas de su tarea historiográfica. Se ha dicho que, pese a la influencia de los grandes cronicones, el licenciado poseía un "acertado y severo concepto de la ciencia histórica" y que lo que le distinguia como buen historiador era ula extraordinaria importancia que concedía al documento, como fuente y como testimonion(109). A la luz de cuanto llevamos expuesto, diremos que al menos es preciso relativizar tales asertos. Sin entrar en juicios de valor, hay que anotar que la obra historiográfica de Cascales es, simplemente, el producto consecuente de una mentalidad, y a través de ella, de toda una época.

Con motivo de nuestra ojeada a las Cartas... se dejó aclarada cuál era la concepción de la historia en Cascales, y que en ella se abria el camino a un finalismo ajeno a lo que, no hoy, sino incluso a finales del siglo XVII, se podía entender como historia. Del mismo modo que entre el erasmismo y los novatores se abre un gran vacio, en el espacio comprendido entre la desaparición de hombres como Juan Bautista Pérez y el surgimiento de los críticos históricos del Barroco (Nicolás Antonio, Mondéjar...) se intercala la gran floración del cúmulo de la historiografía localista, apologética y polémica, intimamente conectada con la enorme difusión de los falsos cronicones(110), desprovista de sentido crítico y puesta al servicio de los intereses y valores de un grupo determinado o del propio sistema en general. Cuestión esta en la que ya hemos insistido largamente. 
Desde luego, el documento (aunque en una obra como la Historia del Colegio... lo proporcionen casi exclusivamente los repertorios falsos de los cronicones), e incluso el resto arqueológico, ocupa un lugar central en las obras históricas del licenciado, y no vamos a ser nosotros quienes nieguen un mérito en esto. La propia definición que de las leyes de la historia contiene la Dedicatoria de los Discursos puede parecer un dechado de pulcritud histórica: "La primera, que no digamos mentira: la segunda, que no callemos la verdad: la tercera, que odio, ni amor, no nos haga sospechososn (111). Sin embargo, nada más contradictorio con lo enunciado que las prácticas de Cascales cuando se dedica a escribir historia. La utilización (posiblemente no llegó a plantearse la veracidad de los textos de los cronicones) de datos no sólo falseados, sino inventados totalmente, tiene su prueba concluyente en la incondicional adhesión al cronicón de Dextro; que siempre escribió guiado por un "amor" de patria o de grupo es igual de claro (a Cartagena, a Murcia, a la diócesis de Cartagena...). Es la segunda ley, empero, la que plantea el problema más importante. En el fondo, no se trata propiamente de que se diga verdad, sino qué verdad se dice: una cuestión de criterio histórico y de definición sobre la consideración del dato histórico y de cómo debe ser interpretado. Una vez más, reaparece la cuestión de la falta de una razón crítica autónoma, causada por toda la multiplicidad de circunstancias que se han analizado, pero sobre todo por el establecimiento de un finalismo sobre la historia. Ya se vieron los textos que aludian a la naturaleza de la historia al comentar la epistola en alabanza de la gramática: ese es el esquema que realmente siguió Cascales cuando se convertía en historiador, considerando su tarea reducida a relatar con orden y estilo los acontecimientos del pasado, a cuyo conocimiento se accedía a través - naturalmente- de los documentos. Por supuesto que Cascales tenia gran amor por el documento, y que su conciencia integra (una herencia del humanismo) no le permitió llegar hasta el extremo de inventarlos, como hiciera un Román de la Higuera. Pero de la historia se pretendia sacar una lección, un ejemplo, nunca descubrir en ella causas, ni mucho menos relaciones y leyes (la historia como escenario de lo humano, por naturaleza contingente y aleatorio); como él mismo decía en aquellos textos, hecho histórico sólo es propiamente el que tiene como protagonistas a personas 0 a instituciones ilustres, capaces de proporcionar elevados ejemplos. Por el contrario, adoptar una postura critica implica no sólo abandonar los ditirambos, sino, normalmente, chocar con el sistema social ( $y$ ahi están los esfuerzos ilustrados en el terreno de la historiografía). Cascales, por el fin que pretendió aplicar a la historia y por sus propios presupuestos ideologicos, estaba situado en las antípodas de cualquier criticismo.

Precisamente la última de las consecuencias de estos planteamientos es el amor por la patria local que le lleva a escribir sus tres obras históricas: el Discurso de la ciudad de Cartagena, opúsculo producto de las 
circunstancias y escrito en agradecimiento a la ciudad de Cartagena, que le acogió antes que la propia Murcia cuando buscaba trabajo como preceptor; los Discursos históricos... y la Historia del Colegio de San Fulgencio... De modo indudable, estas tres obras, por sí solas, ya necesitarian un estudio que rebasaría ampliamente los márgenes de cualquier artículo. Por ello terminamos nosotros con unas pocas notas acerca de las dos últimas.

Por lo que toca a los Discursos..., hay que subrayar precisamente -en conexión con lo expuesto al referirnos a la teoría de la nobleza- algo que nos parece de interés. Murcia, a la que van dedicados, no es aquí ninguna abstracción. Murcia es, fundamentamente, la nobleza murciana: el hecho de dar lustre a la ciudad implica el dárselo a su nobleza, por cuanto es el estamento que la gobierna y que la simboliza y representa a nivel nacional. Desde esta perspectiva, resulta totalmente lógica la estructura de los Discursos... Una narración general de la historia de Murcia desde su origen hasta el reinado de Felipe II, seguida de un capltulo-bisagra sobre la nobleza, que prepara el terreno para las historias particulares de cada linaje a través de sus respectivos estudios genealógicos (150 páginas en una obra de 550). El hecho tan significativo de que fuera el propio concejo municipal murciano quien encargase a Cascales la redacción de la obra(112), $y$ ante la contemplación de la intencionalidad de la misma, creemos que - por cuanto debe responder a algo más concreto que la simple glorificación de las excelencias históricas de Murcia- denota muy posiblemente la existencia de algún tipo de crisis o tensión en el seno del grupo privilegiado murciano, que bien pudiera corresponderse con el momento en que, ya constituido un grupo oligárquico local fuerte y numeroso, comienza el corte de las vías de acceso para integrarse en él, encargando una historia que definiese a sus miembros(113) y les diera argumentos para asegurar su posición; o, más lejanamente, quizá el encargo respondiese a un intento de recuperación del prestigio perdido a nivel nacional por este grupo tras el escándalo causado por la ofensiva inquisitorial que favoreció la difusión de la idea de que el Ayuntamiento de Murcia era poco menos que un nido de conversos (114).

En cuanto a la Historia del Colegio..., no es tan fácil precisar los motivos que le llevaron a escribirla. No obstante, el tema de la historia eclesiástica del obispado de Cartagena habia sido tratado siempre en sus anteriores obras históricas. No ofrece duda, en cambio, la intencionalidad que le movía. La descripción de la entrada en Murcia de las reliquias de San Fulgencio y de Santa Florentina reclamadas por el obispo Dávila y de la fundación del Seminario de San Fulgencio, da pie a Cascales para remontarse bastante alto. Lo que más destaca en el manuscrito es que el linaje de los reyes de España se retrotraiga hasta los monarcas visigodos. Esta tesis, en un momento tan cercano al de las crisis que azotaron la monarquia 
hispánica en torno a 1640, denota la toma de posición del licenciado, cargada de claras connotaciones políticas. Frente a la Hispania romana que defiende un Escolano, la perspectiva (castellanizante y centralista) de la "España cuyo origen político hay que buscarlo en el "destruido" reino visigodo. Un cortejo de cuestiones secundarias acompañan al planteamiento; sobre todo, la exaltación de la unión entre el catolicismo y la monarquia desde Recaredo, y el mito de la destrucción de España a manos del Islam y su posterior reconstrucción. Por lo demás, aparece alguna otra cuestión de menor rango: se reivindican como cartageneras y murcianas las figuras de San Fulgencio, San Isidoro, etc., a la que va unida la de la propia antigüedad e importancia de la diócesis, unas reglas upara el buen recogimiento de las monjas"... La base documental de la obra, casi con exclusividad, la ofrecen los cronicones de Flavio Dextro y Marco Máximo, pero también hay referencias a los de fray Francisco de Bivar, Victor Uticense y otros. Por supuesto, con semejante base, hablar de critica es algo que carece absolutamente de sentido, aun cuando, pretendiendo hacer gala de esa capacidad, Cascales se dedica a enmendar lugares de Ambrosio de Morales o de Andrés Resende.

A pesar de que la senilidad pesaba sobre el licenciado, lo que realizó en la Historia del Colegio de San Fulgencio... es -y a ello hemos consagrado este trabajo- prolongación coherente, y no fruto de un ocasional error, de unos planteamientos presentes, explícita o implicitamente, en toda la extensión de su obra. Ningún texto como el que sigue para resumir su actitud y dar punto final a nuestra exposición:

"Gracias a Dios que tenemos oi a Flavio Dextro, M. Maximo, i a Leuprando, que son escriptores abonados de aquel tiempo (el de los godos) que nos dizen la verdad, aunque mui succintamenten(115). 


\section{NOTAS:}

(1) Biblioteca Nacional, manuscrito 2562. Códice de 160 folios en $4 .^{\circ}$, doble foliación no correlativa, falto de portada y de la última hoja. Considerado anónimo, por carecer de título (el que lleva es facticio) y de autor, la atribución se hizo fácilmente a la vista de las notas autobiográficas que introdujo Cascales, así como por la aplicación del cotejo caligráfico y por la existencia de otra copia manuscrita en la Biblioteca Provincial de Toledo (Cf. J. GARCIA SORIANO, El humanista Francisco Cascales. Vida y Obra, Madrid, 1924, p. 103). En 1950, Giménez de Gregorio ("El Colegio-Seminario de San Fulgencio de Murcia», Anales de la Universidad de Murcia, volumen años 1949-1950), daba la noticia de que el manuscrito habla desaparecido. Afortunadamente, debió tratarse de un momentáneo extravío, puesto que en una reciente visita hemos comprobado que el manuscrito seguia en su lugar original.

(2) J. GARCIA SORIANO, op. cit., pp. 100-106.

(3) Cf. J. A. MARAVALL, La cultura del Barroco, Madrid, 1980.

(4) J. GARCIA SORIANO, op. cit.

(5) Es el caso de la reedición de los Discursos históricos de la ciudad de Murcia y su Reyno, Academia de Alfonso X el Sabio, Murcia, 1980. Se trata de una edición facsímil de la de 1775.

(6) J. GARCIA SERVET, El humanista Cascales y la Inquisición murciana, Madrid, 1975.

(7) Por citar algunas, Cf. M. MENENDEZ PELAYO, Historia de las ideas estéticas en España, vol. II pp. 239-246; A. MARTI, La preceptiva retórica española en el Siglo de Oro, Madrid, 1972 , pp. 273-278.

(8) Vid. supra.

(9) A. GARCIA BERRIO, Introducción a la poética clasicista: Cascales. Barcelona, 1975.

(10) Es precisamente la edición que sirve de base a la facsimilar de 1980. | y |I.

(11) Sobre todos estos aspectos, Vid. J. GARCIA SORIANO, op. cit., "parte primera», caps.

(12) -Discurso de la ciudad de Cartagena, dirigido a la misma, Valencia, 1598, Juan Chry. sóstomo Garritz.

- Tablas poéticas, terminadas en 1604 y publicadas en 1617.

- Discursos históricos..., terminados en 1614 y publicados en 1621.

- "Prólogon al Discurso iurídico por la Inmaculada., de Alonso de Mergelina, 1628.

- Cartas filológicas, publicadas en 1634 (recopilación de correspondencia escrita en las dos décadas anteriores).

- Epistola Horatii Flacci de arte poetica in methodum redacta... (en torno a 1636).

- Florilegium Artis versificatoriae..., 1640.

Sin publicar o perdidas han quedado algunas otras piezas:

- Historia del Colegio de San Fulgencio... (1639 aprox.)

- Epopeya del Cid... (1590-1600 aprox.)

- Versión casteliana de la Epistola ad Pisones (1601)

Con toda seguridad, Cascales escribió o publicó algunos otros fragmentos de menor importancia (Cf. GARCIA SORIANO, op. cit.).

(13) J. GARCIA SERVET, op. cit., capitulos I y II.

(14) L. GIL FERNANDEZ, Panorama social del humanismo español (1500-1600), Madrid, 1981, pp. 466-467.

(15) En tal sentido debemos entender las palabras que escribe en el Discurso de Cartagena...: uni a mí me falta Murcia, ni yo la hago en ella, por no ser de consideración mi asistencia... por no vivir pobre entre ricos, mal conocido entre caballeros, olvidado entre deudos, y estrangero (sic) en mi patrian. (Fol. 3)

(16) Cf. GARCIA SERVET, op. cit., cap. IV. 40-43.

(17) Cartas filológicas, Ed. J. GARCIA SORIANO, Madrid, 1961. Década III, Epistola III, pp. 
(18) Id. Década I, Ep. II, pp. 35-36.

(19) J. GARCIA SORIANO, El humanista..., pp. 64-65.

(20) J. TORRES FONTES, artículo en Murgetana, número 23.

(21) Ib/dem.

(22) L. GIL, op. cit, pp. 299 y ss.

(23) Cf. J. GARCIA SORIANO, El humanista..., pp. 44 y 100; J. TORRES FONTES, loc. cit.

(24) J. A. MARAVALL, op. cit. p. 55.

(25) Ibldem., caps. 1 al 5.

(26) A. MESTRE, "Las corrientes de espiritualidad en la Valencia de la primera mitad del siglo XV|n, Actas congreso en el centenario de San Luis Beltrán, Valencia, 1982 (en prensa).

(27) M. BATAILLON, Erasmo y Espana, F. C. E., 1966, pp. 770-772.

(28) A. GARCIA BERRIO, op. cit. pp. 9-10.

(29) Ibid., p. 19.

(30) J. A. MARAVALL, op. cit., p. 32.

(31) A. GARCIA BERRIO, op. cit., p. 25.

(32) J. A. MARAVALL, op. cit., p. 134.

(33) Ibid., p. 159.

(34) J. GARCIA SORIANO, op. cit., p. 62.

(35) J. A. MARAVALL, op. cit., p. 174.

(36) J. GARCIA SORIANO, op. cit., p. 123.

(37) Ibid., p. 124.

(38) Cf. J. A. MARAVALL, Poder, honor y élites en el siglo XVII, Madrid, 1979.

(39) J. A. MARAVALL, La cultura..., pp. 280-281.

(40) J. GARCIA SORIANO, op. cit., p. 125.

(41) Cartas filológicas, Déc. II, Ep. III «Al Apolo de España, Lope de Vega Carpio. En defensa de las comedias y represantación de ellasn.

(42) A. GARCIA BERRIO, op. cit., p. 27.

(43) Cartas..., Déc. III, Ep. X, p. 232.

(44) J. A. MARAVALL, "Empirismo y pensamiento político. (Una cuestión de orígenes)», en Estudios de historia del pensamiento español. Siglo XVII., 1975, p. 16.

(45) $\mathrm{lb} / d$.

(46) Ib/d.

(47) Discursos históricos..., "Dedicatoria...".

(48) J. GARCIA SORIANO, op. cit. p. 123.

(49) Ibid., pp. 134-136.

(50) Cartas..., "Al lector", Déc. I, p. 11.

(51) Ibid., p. 11.

(52) Ibid.

(53) Cartas..., Déc. III, Ep. III, p. 66.

(54) A. MESTRE, «Religión y cultura en el siglo XVIII español», en Historia de la Iglesia en España, B. A. C. tomo IV, pp. 680-681.

(55) A tal efecto, Cf. los índices onomásticos que acompafian a las Cartas...

(56) Cartas..., Déc. III, Ep. III, pp. 45-50.

(57) Ibid., p. 66. 
(58) Cartas..., Déc. II, Ep. IV, p. 73.

(59) Cartas..., Déc. I, Ep. II, p. 47.

(60) Cartas..., "Al lectorn, p. 9.

(61) Cartas..., Déc. III, Ep. IV.

(62) Cartas..., Déc. III, Ep. I.

(63) lbid., p. 11.

(64) Cartas..., Déc. I, Ep. IV, p. 86.

(65) M. BATAILLON, loc. cit.

(65 bis) Discursos históricos..., "Dedicatoria...”

(66) Cartas..., Déc. I, ep. II: "Contra las letras y todo género de artes y ciencias. Prueba de ingenion; Id. Ep. IV: "En defensa de los capones cantores, contra quien había escrito"; Déc. II, Ep. l: "Contra los Bermejos".

(67) Cartas..., Déc. I, Ep. IV. p. 81.

(68) Cartas..., Déc. I, Ep. VII; Déc. III, Ep. VIII.

(69) Cartas..., Dec. III, Ep. IV; Déc. II, Ep. VI; Id. Ep. VIII.

(70) Cartas..., Déc. I, Ep. I, «A D. Alonso Fajardo... Trata de cómo se ha de gobernar en su viaje con su genten; Id. Ep. III: «A un cabaliero... Instrucción cómo se ha de haber asi en la guerra como haciendo su oficio de regidor»; Déc. III, Ep. V «Al licdo. Pedro Ferrer... Es una instrucción para bien gobernar".

(71) Cartas..., Déc. III, Ep. IV, p. 72.

(72) Cartas..., Déc. I, Ep. II, pp. 37-38.

(73) Cartas..., Déc. I, Ep. I, p. 23.

(74) Vid. L. GIL FERNANDEZ, op. cit., cap. 5 de la segunda parte.

(75) Itid., p. 283.

(75 bis) Cf. JOUCLA-RUAU, Le tacitisme de Saavedra Fajardo, Ed. Hispaniques, Paris, 1977. En este trabajo, aparte indicarse la filiación neoestoica de Cascales, el preceptor aparece como influencia de primer orden en el humanismo de Saavedra.

(76) Cartas..., Déc. I, Ep. I, p. 28.

(77) Las perspectivas de la contingencia la extiende Cascales hasta el puro campo de la fisiología humana, lo que le conduce a cuestionar los métodos empíricos utilizados por la medicina y por supuesto el carácter racional de la realidad: "Dime médico: ¿Cómo conoces tú las partes interiores del cuerpo afectas? ¿Cómo te avienes en tanto número y diversidad de partículas del cuerpo humano? ¿Cómo conoces las causas secretas de naturaleza por los efectos mudos y muchas veces contrarios? ¿Cómo aplicas remedios a cosas distintas, confusas y misceláneas? Atado estás; ¿qué has de hacer en tanta perplejidad?, ¿qué? Aventurar y jugar al tablero la vida del hombre." (Cartas..., Déc. I, Ep. II, p. 46). La última frase tiene un contenido claramente moral.

(78) J. A. MARAVALL, Poder, honor..., p. 37.

(79) Ib/d., p. 39.

(80) Se trata del Discurso XVII, De la nobleza.

(81) Cartas..., Déc. II, eps. VIII y IX.

(82) Cartas..., Déc. II, ep. VIII, pp. 182-183.

(83) Cartas..., Déc. II, ep. VII.

(84) Cartas..., Déc. I, ep. III.

(85) Id., p. 57.

(86) J. A. MARAVALL, Poder, honor...

(87) Ibid., pp. 43-44.

(88) Ib/d., p. 48. 
(89) Discursos históricos, p. 347.

(90) Ibid., p. 340.

(91) No olvidemos que la redacción de los Discursos... es, en su conjunto, anterior a la de las Cartas...

(92) Discursos..., p. 343.

(93) Ibid., p. 340.

(94) J. A. MARAVALL, La cultura..., p. 390.

(95) Discursos..., p. 345.

(96) Ibid., p. 345.

(97) Ib/d., p. 341.

(98) Ibid., p. 346.

(99) Ib/d., p. 341.

(100) Ibid., p. 344.

(101) Como es natural, Cascales omite toda alusión al problema de la limpieza de sangre.

(102) Discursos..., p. 341.

(103) Ibid., p. 344.

(104) Ibld., p. 343.

(105) Ibid., p. 344. Esta advertencia la dirige muy concretamente al estrato inferior de la nobleza (los hidalgos), a quienes además trata con un complice nos.

(106) Ib/d., p. 341.

(107) J. A. MARAVALL, Poder, honor..., p. 32.

(108) Discursos..., p. 348.

(109) J. GARCIA SORIANO, op. cit., pp. 91-92.

(110) Es un hecho la correspondencia Cascales-Román de la Higuera. Asimismo, téngase presente la profunda veneración que Cascales tuvo por el durante un tiempo prelado cartagenero Sancho Dávila y Toledo. Sobre el paticular, remitimos a la obra de J. GODOY ALCANTARA, Historia critica de los falsos cronicones, 1868, reed. facsímil 1981, Ed. T. C. D., Madrid.

(111) Vid. dicha "Dedicatoria..."

(112) J. GARCIA SORIANO, op. cit., p. 89, demostró que la preocupación municipal hacia la promoción de obras de este tipo era anterior.

(113) La carta VIII de la Déc. III, "De los Delgadillos, Manueles..." la escribió a consecuencia de las protestas que los miembros de estos linajes formularon por no haber sido incluidos en los Discursos...

(114) J. OWENS, "Situación social y poder politico en Murcia, 1490-1570", Historia de la región murciana, Murcia, 1980, tomo $V$, pp. 31-32.

(115) Ms. cit., últímos párrafos del capítulo 4. 